\title{
CAPABILITY AND HAPPINESS Conceptual difference and reality links
}

\author{
Ruut Veenhoven
}

Journal of Socio-Economics, 2010, 39: 344-350, DOI:10.1016/j.socec.2009.11.007

\begin{abstract}
Happiness is not the same as capability, but the matters are related. Capability is obviously required for living a happy life and happiness feeds back on capability in several ways. Capabilities affect happiness not only at the individual level, but also indirectly at the societal level. For instance: school education does not seem to make pupils any happier, but a high level of education is required for modern society that does add to happiness.

Insight in the interrelations between capability and happiness is required for making policy choices. If the prime aim is greater happiness for a greater number, one must know what capabilities are most functional for happiness in the given conditions. If the cultivation of capabilities is prioritized, one must at least acknowledge the possible loss of happiness. Inspection of the available data does not reveal much conflict.
\end{abstract}

Key words: Capability, Happiness, Life-chances, Cross-national, Longitudinal, Research synthesis

JEL classification: B00, D63, I00, I121, I130, Y80

\section{INTRODUCTION}

The 'capability approach' is a strand in welfare economics that focuses on "freedom to promote valuable beings and doings" rather than on "utility" in the sense of "income, commodities, or people's happiness" (HDCA 2009). The capability approach builds on the work of Sen (1985) and Nussbaum (2000).

In quality-of-life research, this capability approach is often contrasted with the 'happiness approach' of which Diener (1999) and myself (Veenhoven 1984) are representatives. In this paper I explore the differences between these approaches. What is the conceptual difference between 'capability' and 'happiness'? How do these matters relate? And what are the policy implications of focusing on one or the other?

\section{CONCEPTUAL DIFFERENCE}

The concepts 'capability' and 'happiness' concern both 'quality-of-life'. Their differences can therefore be elucidated in the context of an analysis of that concept. In an earlier publication I have distinguished four qualities of life (Veenhoven 2000), which are presented in scheme 1.

\section{Qualities of life}

This classification depends on two distinctions. The columns denote a between chances for a good life and actual outcomes of life. Chances and outcomes are related, but are certainly not the same. The rows denote a distinction between external and internal qualities. In the first case the quality is in the environment, in the latter it is in the individual. Together, these two dichotomies mark four qualities of life. 


\section{Livability of the environment}

The left top quadrant denotes the meaning of good living conditions. Often the terms 'quality-oflife' and 'wellbeing' are used in this particular meaning, especially in the writings of ecologists and sociologists. Economists sometimes use the term 'welfare' for this meaning. 'Livability' is a better word, because it refers explicitly to a characteristic of the environment and does not carry the connotation of Paradise. Politicians and social reformers typically stress this quality of life.

\section{Life-ability of the person}

The right top quadrant denotes inner life-chances. That is, how well we are equipped to cope with the problems of life. This aspect of the good life is also known by different names. Especially doctors and psychologists also use the terms 'quality of life' and 'wellbeing' to denote this specific meaning. There are more names however. In biology the phenomenon is referred to as 'fitness' and this term aptly coveys the message that abilities must be seen in the context of environmental demands. On other occasions it is denoted by the medical term 'health', in the medium variant of the word. I prefer the simple term 'life-ability', which contrasts elegantly with 'livability'. This quality of life is central in the thinking of therapists and educators.

\section{Utility of life}

The left bottom quadrant represents the notion that a good life must be good for something more than itself. This presumes some higher value, such as ecological preservation or cultural development. In fact, there is a myriad of values on which the utility of life can be judged. There is no current generic for these external turnouts of life. Gerson (1976: 795) referred to these kinds as 'transcendental' conceptions of quality of life. Another appellation is 'meaning of life', which then denotes 'true' significance instead of mere subjective sense of meaning. I prefer the more simple 'utility of life', admitting that this label may also give rise to misunderstanding ${ }^{1}$. Moral advisors, such as your pastor, emphasize this quality of life.

\section{Satisfaction with life:}

Finally, the bottom right quadrant represents the inner outcomes of life. That is the quality in the eye of the beholder. As we deal with conscious humans this quality boils down to subjective appreciation of life. This is commonly referred to by terms such as 'subjective wellbeing', 'lifesatisfaction' and 'happiness' in a limited sense of the word. There is no professional interest group that stresses this meaning

\section{Place of capability}

The term 'capability' denotes chances for a good life, rather than the outcomes of life. Sen's basic idea was that developmental policy should focus on opportunities for improving one's lot rather than on the economic outcomes. So we must place capability in the upper part of scheme 1.

The word 'capability' refers to 'being able', in Sen's work typically being able to improve one's situation and in Nussbaum's being able to live a truly human life. 'Being able' requires both freedom from external restraints and personal skills. Freedom from external restraints belongs in the top-left quadrant of scheme 1, while the personal competency to use environmental chances belongs in the top-right quadrant. In Sen's work, the emphasis is in the top-left quadrant, in particular where he argues against discrimination. Yet he also highlights education, which is an individual quality. In Nussbaum's work the emphasis is in the top-right quadrant. Most of the capabilities on her list are inner aptitudes, e.g. practical reason and imagination. Yet her she also mentions protection against violent assault, which is an environmental factor. 
This duality of the notion does not reflect so well in the word 'capability', which typically refers to individual quality in daily language. It reflects better in the term 'substantive freedoms' that is used as a synonym. The term 'freedom' is mostly associated with absence of social restraints. In philosophical language the word is also used for an individual's ability to take control over his or her life. In that context Berlin (1955) distinguishes between 'negative' and 'positive' freedom and Bay (1965) between 'social freedom' and 'psychological freedom'.

\section{Focus on individual capabilities}

When used in this dual sense, the term 'capability' is equivalent to 'life chances' and suffers the same problems of that notion. One of these problems is that it is a wide generic, the wideness of which leads to picking some particular aspects, as in Nussbaum's list of capabilities. Another problem is that one looses sight on the interrelation between environmental demands and individual skills. The relevance of skills depends on their functionality in a given environment and that is reflected in the word 'fitness' in biological terminology. Calling these things by the same name is not helpful for understanding their interrelation. For this reason I focus on capability in the limited sense of individual life-ability.

\section{Kinds of individual capabilities}

In this paper I distinguish between general capability and specific capabilities. General capability is what biologists denote as 'fitness' and involves all aptitudes that a relevant for a good life. Specific abilities are many, e.g. physical abilities such as 'strength' and mental abilities such as 'musicality'. Nussbaum does not make that distinction, on her list of 10 vital capabilities figures 'bodily health' (number 2) next to 'concern for nature' (number 8).

General capability: Another word for general capability is 'health'. Health can be defined negatively in terms of absence of defect or positively in terms of excellence of functioning. When we say that someone is in 'good health' we mostly mean that there is nothing wrong with this person's body, when we say that someone is 'intelligent' we typically mean that this person thinks better than average. Another common distinction is between physical health and mental health. Physical health is number 2 on Nussbaum's list of 10 vital capabilities. Mental health is not mentioned by Nussbaum, but should not be disregarded.

Specific capabilities: As noted there are many specific capabilities. In this paper I limit to the capabilities on Nussbaum's list that have figured in empirical research on happiness. These are:

- Senses, imagination, and thought: being able to use the senses, to imagine, think, and reason - and to do these things in a "truly human" way, a way informed and cultivated by an adequate education (number 4 ).

- Emotions: being able to have attachments to things and people outside ourselves; to love those who love and care for us, to grieve at their absence; in general, to love, to grieve, to experience longing, gratitude, and justified anger (number 5).

- Practical Reason: being able to form a conception of the good and to engage in critical reflection about the planning of one's life (number 6).

- Affiliation: being able to live with and toward others, to recognize and show concern for other human beings, to engage in various forms of social interaction; to be able to imagine the situation of another (number 7).

○ Play: being able to laugh, to play, to enjoy recreational activities (number 9).

\section{Place of happiness}

The word 'happiness' has been used as a generic for all the qualities of life in scheme 1 and also 
for each of these separately. The word is now increasingly used in the sense of subjective wellbeing, that is, the 'satisfaction' quadrant at the bottom-right in scheme 1 .

\section{Kinds of satisfaction}

This brings us to the question of what 'satisfaction' is precisely. This is also a word with multiple meanings and again we can elucidate these meaning using a simple scheme. Scheme 2 is based on two distinctions; in columns between satisfaction with parts of life versus satisfaction with life $a s-a$-whole, and in rows between passing satisfaction and enduring satisfaction. These two bipartitions yield again a four-fold taxonomy.

- Pleasure: Passing satisfaction with a part of life is called pleasure. Pleasures can be sensoric, such as a glass of good wine, or mental, such as the reading of this text. The idea that we should maximize such satisfactions is called 'hedonism'.

- Part-satisfaction: Enduring satisfaction with a part of life is referred to 'domainsatisfaction' when it concerns a field of life, such as work or marriage, and 'aspectsatisfaction' when it concerns a facet of life, such as its variety. Sometimes the word happiness is used for such part-satisfactions, in particular for satisfaction with one's career.

- Peak experience: Passing satisfaction can be about life-as-a-whole, in particular when the experience is intense and 'oceanic'. This kind of satisfaction is usually referred to as 'top' or 'peak' experience. When poets write about happiness they usually describe a feeling of this kind. Likewise religious writings use the word happiness often in the sense of a mystical ecstasis. Another word for this type of satisfaction is 'enlightenment'.

○ Life-satisfaction: Enduring satisfaction with one's life-as-a-whole is called life-satisfaction and also commonly referred to as 'happiness' or 'subjective well-being'. I have delineated this concept in more detail elsewhere (Veenhoven 1984': chapter 2) ${ }^{3}$.

\section{Focus on life satisfaction}

Which of these kinds of satisfaction is should we use for assessing the relation with capabilities? Evidently that is the last meaning of overall life-satisfaction or 'happiness'. What we want to know is what capabilities are required for leading a satisfying life. In that context the concern is not with short lived pleasures and neither with incidental peak experiences. Likewise, satisfaction in particular domains of life does not denote a satisfying life, e.g. not high job-satisfaction if that goes at the cost of low satisfaction with family life. So I will focus on happiness in the sense of satisfaction with one's life-as-a-whole.

There are many misgivings about the value of happiness, such as that happiness is mere contentment and that it typically results from an unrealistically rosy view on reality. In this context I cannot go in the details of these qualms ${ }^{4}$. Suffice to say that in assessing how happy we are, we use our mood as the prime source of information and that mood reflects the degree to which basic needs are met. As such, happiness signals how well we thrive biologically (Veenhoven 2006) and is part of human 'flourishing, 5 .

\section{$3 \quad$ CAPABILITY $\rightarrow$ HAPPINESS}

What capabilities are conducive to happiness? This question can be addressed at two levels: the individual level and the societal level. At the individual level the focus is on the relation between skill and happiness of particular persons. At the societal level the focus is on the relation between the level of capability in societies and the average happiness of citizens. Effect can differ between these levels. As we will see below, IQ is related to happiness at the societal level, but not at the individual level. 
In the following review of research, I will draw on the World Database of Happiness (Veenhoven 2008b), in which I gather the results of empirical happiness research yielded with indicators of happiness that fit the above defined concept. I will particularly draw on the collection of Correlational Findings (abbreviated WDH-CF) that involves the results of both many cross-sectional studies and of fewer longitudinal investigations. The precise finding places in that collection are be mentioned in footnotes, so that the interested reader can check my summary conclusions. The findings are too many and too diverse to be discussed separately in this paper ${ }^{6}$.

\section{Individual capabilities}

Above I have distinguished between general capability and specific capabilities. What has research learned us about the effects on happiness of these capability variants? The findings are summarized in scheme 3.

\section{General capability}

As noted above, general capability is reflected in measures of 'health'. There is a sizable body of research on health and happiness, the findings of which are summarized in the upper part of Scheme 3.

Unsurprisingly, health is correlated with happiness. What may surprise is that the correlation with mental health is stronger than with physical health and the correlation with positive mental health is strongest of all ${ }^{7}$.

This correlation is at least partly due to an effect of health on happiness. It is beyond doubt that physical illness reduces happiness, even though several studies show remarkable adaptation among seriously sick and handicapped people ${ }^{8}$. It is no surprise either that recovery from physical illness tends to be followed by a rise in happiness. Change in mental illness seems to affect happiness even more, in particular getting depressed and recovery from depression (e.g. Bergsma et. al 2009). There is less evidence for a causal effect of change in positive health on happiness, but such effect probably exists.

\section{Specific capabilities}

What specific talents are required for happiness? Below I limit to the abilities on Nussbaum's list of which the relationship with happiness has been investigated.

School intelligence: Capability number 4 on Nussbaum's list is described as "being able to use the senses, to imagine, think, and reason - and to do these things in a 'truly human' way, a way informed and cultivated by an adequate education". This corresponds with the set of aptitudes that is measured with IQ tests, which have been developed for assessing the mental abilities trained in school. Several studies have assessed the relation between IQ and happiness and contrary to expectation these studies found no correlation ${ }^{9}$. A follow-up study found no long-term effect on happiness either ${ }^{10}$. Likewise, there is little correlation between level of education and happiness, high-school graduates being about as happy as compatriots with a university degree ${ }^{11}$. This lack of a correlation could be due to a tendency of unhappy people to invest more in schooling, which would suppress an otherwise positive correlation. Yet, follow-up studies do not show an effect either of earlier education on later happiness, not even among talented people ${ }^{12}$. So it seems that this kind of capability does not add to happiness. It is unlikely that the things we learn in school have no effect on happiness at all, but it could be that above average school intelligence does not add to happiness any more in highly educated societies or that the benefits of education are balanced by its costs, such as 
the spending of one's entire youth in school benches.

Social intelligence: The capabilities 'Emotions' and 'Affiliation' on Nussbaum's list fit with the notion of 'social intelligence'. This aptitude appears to be strongly correlated with happiness. This appears in correlations with self rated ability as well as with ratings by others, such as clinical ratings and ratings by trained peers ${ }^{13}$. Related personality traits are also correlated with happiness, such as assertiveness ${ }^{14}$, empathy ${ }^{15}$, extraversion ${ }^{16}, \operatorname{kindness}^{17}$, openness ${ }^{18}$ and sociability ${ }^{19}$. Happiness is also strongly correlated with indicators of social functioning, such as with family relations ${ }^{20}$, friendships ${ }^{21}$, popularity ${ }^{22}$, social participation ${ }^{23}$ and social support ${ }^{24}$. Though 'social functioning' is not quite the same as 'social ability' it is likely that the correlations also reflect a link with ability. As yet there is no evidence that improvement of social ability results in greater happiness, but this is also likely to be the case.

Leisure skills: Ability to 'Play' is number 9 on Nussbaum's list and this can be taken as 'leisure skills'. Does this capability add to happiness? A large body of research shows positive correlations between involvement in leisure activities and happiness ${ }^{25}$ and between leisure satisfaction and happiness ${ }^{26}$, a few follow-up studies suggesting a causal effect on happiness $^{27}$. Yet leisure 'activity' is not quite the same as leisure 'ability'. There are no studies that assessed the effect of leisure capabilities such as being able to play the piano or expertise in gardening. Only in the case of sports we have a clue since skill level in sports was found to be correlated with happiness among British students ${ }^{28}$.

Moral competence: Moral development is not a separate topic on Nussbaum's list of core capabilities, but is involved in her descriptions of 'Practical reason' (6), concern for other people $(5,7)$ and other species $(8)$. Empirical studies show a strong correlation between happiness and adherence to social values ${ }^{29}$ and the few follow-ups suggest a causal effect ${ }^{30}$. Personality traits such as solidarity ${ }^{31}$, trust $^{32}$ and trust-worthiness ${ }^{33}$ are also more common among the happy. This pattern appears not only in self-rating of morality, but also in ratings by peers and teachers ${ }^{34}$.

\section{Level of capabilities in nations}

Some of these individual level relationships are also observed at the nation level. Data are less abundant and causality is more difficult to assess:

\section{General capability}

There is a strong correlation between average physical health on nations and average happiness, both with absence of illness and longevity ${ }^{35}$. Improvement of physical health in nations tends to be paralleled by a rise in happiness (Veenhoven 2005a) and this is an indication of a causal effect. The data on mental health in nations are less abundant and do not allow a comparison with the strength of the effect of physical health.

\section{Specific capabilities}

Of the four capabilities discussed above, three have also been investigated at the national level, that is, school intelligence, social intelligence and moral competence.

School intelligence: In an analysis of 81 nations 1980-90 Lynn and Vanhanen (2002) found no correlation between average IQ and average happiness, which fits the above mentioned non-correlation at the individual level. Yet consideration of a larger data set does reveal a positive correlation (Choi \& Veenhoven 2009). Likewise, there is a positive correlation between the level of school education in nations and average happiness of citizens ${ }^{36}$. How 
can it be that education adds to happiness at the nation level, but not at the individual level? The answer seems to be that an educated populace is required for the functioning of a modern society and that people flourish well in such societies (Veenhoven 2006), while education as such is not does not add to individual happiness, probably because its benefits are balanced by costs.

Social intelligence: There are no comparable measures of social intelligence in nations and hence no studies that assessed the relation with average happiness. Still, there are clues in cross-national research on related matters. Studies on 'national character' show a tendency of greater happiness in nations the average citizen is more extravert ${ }^{37}$ and trusting ${ }^{38}$.

Leisure skills: Measures of average leisure skill are not available at the level of nations. Performance in top-sports can be compared using medal counts, but top-sport is too much professionalized to be considered as leisure and the skill level of top-sports is not representative for the skill level of the average citizen. So in this case we are empty-handed for the time being.

Moral competence: Several studies have assessed honesty in nations using attitudes to cheating. When crossed with average happiness in nations a strong positive correlation appears ${ }^{39}$, which fits the observed relationship at the individual level. The direction of causality is less well documented in this case and attitudes to cheating do not quite cover wider moral competence. Likewise, there is good evidence that corruption is detrimental to average happiness in nations, even in cultures where favoritism is morally approved ${ }^{40}$.

\section{Causal mechanisms}

Most of the above discussed capabilities seem to add to happiness and this begs the question what causal effects are involved.

Evidently, capabilities foster happiness to the extent that they are functional in mastering the problems of life. In that line biologists link 'fitness' to 'survival', while acknowledging that the functionality of capabilities depends on environmental demands. In this light it is understandable that not all skills learned in school are equally conducive for happiness and that social skill is typically more relevant than knowledge of mediaeval poetry. Capabilities can also be functional for the social system and as such contribute to happiness indirectly. We saw this in the case of school intelligence, which adds to happiness only at the nation level.

Less evident is that capabilities add to happiness also in the process of functioning. Nature encourages the use of capabilities with links to pleasant affect; we like to use and develop our capabilities even if there is no external benefit. This phenomengm is known as 'intrinsic motivation' and seen as part of a basic need for 'self-actualization. ${ }^{41}$. So, the effect on happiness is partly in the joy of exercise, in German aptly called 'Functidns ust'.

\section{HAPPINESS $\rightarrow$ CAPABILITY}

The observed correlations between capabilities and happiness can also result from an effect of happiness on capability development. What do we know about this causal connection? The World Database of Happiness (WDH-CF) contains only a few follow-up studies on this matter. The scarce results are summarized in the right column of scheme 3 . All these findings concern the individual level. 


\section{General capability}

There is good evidence that happiness fosters physical health and the effect of happiness on health appears to be stronger than the effect of health on happiness. This appears in a 12-year follow-up study among American couples by Hawkins and Booth (2005:456), which showed a stronger correlation between baseline happiness and later health $(r=+.37)$ than between baseline health and later happiness $(\mathrm{r}=+.13)$. As a result, happy people live longer and this was demonstrated in a synthetic analysis of 28 follow-up studies. Happiness does not lengthen life of seriously sick people, such as cancer patients, but it does lengthen the life of healthy people considerable. This means that happiness does not cure, but protects again falling ill (Veenhoven 2008).

Protecting against falling ill concerns 'negative' health. Happiness seems to foster positive health as well. This is at least suggested by experimental studies using mood induction, which show that positive affect has an energizing effect (Lyubomirsky et al. 2005).

Probably, happiness fosters mental health as well. Analysis of a 4-year follow-up study among the general population does indeed show lower incidence of mental disorder among the initially happiest people (Bergsma et. al 2009). There are also indications that happiness fosters positive mental health. Experimental studies show effects on creativeness, psychological autonomy and self-esteem (Lyubomirsky et. al. 2005)

\section{Specific capabilities}

Data are less abundant in this case. Still the following pieces of evidence can be mentioned.

School intelligence: Though there is some same-time correlation between happiness and performance among high school students, happiness does not predict school grades 3 years later $^{42}$. However, happiness in high schoo does predict somewhat greater educational achievement 8 years later ${ }^{43}$. On the other hand, happiness at age 30 appeared not to predict clinical ratings of cleverness in old age ${ }^{44}$.

Social intelligence: There is better evidenqe on effects of happiness on social skill, such as greater kindness ${ }^{45}$ and trust ${ }^{46}$. Probably there are also negative effects, such as greater vulnerability for deception, but these possible costs of happiness have not yet been investigated.

Leisure skill: Though happiness enhances curiosity and openness for new experiences, there is as yet no evidence that happiness makes us better sports or wine tasters. There is no evidence to the contrary either, so the cell in scheme 3 remains empty for the time being.

Moral competence: Happiness predicts later adherence to social value 47 and this indicates an effect of happiness on morality.

\section{Causal mechanisms}

Having established that happiness affects capability, the next question is how. The main causal effect seems to be that happiness fosters activity, activity on its turn fostering the maintenance and development of skills. This explanation fits the view that positive affect works as a go-signal, while negative affect rather instigates caution (Veenhoven 2009). Happiness can also contribute to capabilities in indirect ways: e.g. since happiness facilitates social contact, happy people have more chances to develop social skills than the unhappy who spend more time watching television. All these mechanisms fit Fredrickson's (1998) 'broaden and build' theory of positive affect. 


\section{CAPABILITY VERSUS HAPPINESS?}

In the introduction I referred to a controversy in quality-of-life research between the capability approach and the hedonic approach. Adherents of the capability approach stress the upper right quadrant in scheme 1. They emphasize the importance of life-abilities and regard happiness rather as a by-product of the use and development of capabilities. They sniff of happiness as such, which they denounce as the simplistic joy of 'Happy Hans'. This view lives among educators and therapists as well as among misanthropic philosophers. Advocates of the hedonic approach rather stress the right bottom quadrant in scheme 1 . In their view, the value of capabilities is in their functionality for a happy life. They warn against bookish education and repression of affective experience. This view is more common among the general public, which values happiness typically more than education (e.g. Harding 1986) and supports the view that schools should focus more on happiness (BBC 2006: Q8) and is central in utilitarian moral philosophy.

What do the data tell us about this controversy? First of all, that there is no conflict in most cases. Capability is typically conducive to happiness, while happiness enhances capability. This interdependency is most pronounced in the case of general capability (health) but exist also in most of the specific capabilities discussed here. So one can agree on the same policies in spite of difference in principle.

Still, the case of school intelligence illustrates that policymakers must sometimes show their hand. They cannot ignore the fact that school education does not add to personal happiness, in spite of its obvious economic functionality. Apparently there is 'a loss of happiness' in the educational system, comparable to the "Loss of happiness in market democracies" depicted by Lane (2000). This calls for a critical look at what we teach in schools and how. It also calls for caution against pleas for life-long-learning.

If there is so little conflict, why then still this philosophical controversy?

Part of the answer is in stakeholder interest. As indicated in the above section on conceptual differences, there are vested interest behind conceptions of the good life and in particular in conceptions of the good life in terms of chances (upper row in scheme 1). In that context, educators tend to see the good life as a cultured life and hence themselves as the main producer of the good. Probably for that reason they are receptive for arguments that happiness is not everything and buy myths such as that happiness is relative, that happiness is an immutable trait and that slaves can be happy. As noted, there is no strong vested interest behind the hedonic approach and this may be why these myths still persist.

A related of the answer is that the available knowledge about happiness did not diffuse too well in philosophy. The view of happiness as a biological signal is typically absent in philosophical reflection on happiness and for that reason most philosophers are blind to the obvious relationship between subjective happiness and human flourishing. Likewise there is little acknowledgment of the results of empirical research, such as that happiness is not relative (Veenhoven 1991), that happiness is not an immutable trait (Veenhoven 1995, Headey ) and that slaves will not be happy, even if they do not know better (Veenhoven 2007). I hope that this paper will help to reduce this information lag.

Lastly there is there is of course genuine difference in value-preference. One can prefer a life that meets particular cultural standards over a life that meets human needs and choose accordingly in case of conflict. There is nothing wrong with that, as long as one acknowledges the price of that choice. 
Capability and happiness are different but related. Capability is obviously required for happiness, though not all capabilities are equally functional. Less obvious is that happiness fosters many capabilities, in particular health. In case of reciprocal causality there is little conflict between policies that prioritize either capability or happiness. A review of the available research findings shows much synergy, except in the case of school education. 


\section{REFERENCES}

Anand P, Hunter, G. and Smith, R. (2005)

Capabilities and Wellbeing: Evidence Based on the Sen-Nussbaum Approach to Welfare

Social Indicators Research, 74: 9-55

BBC (2006)

The Happiness Formula

Opinion Poll GfK-NOP poll 421059, Available at:

http://news.bbc.co.uk/nol/shared/bsp/hi/pdfs/29_03_06_happiness_gfkpoll.pdf

Bergsma, A. , TenHave, M. Veenhoven, R. \& DeGraaf, R. (2009)

Mental disorder and subjective wellbeing

Working paper, Erasmus university Rotterdam

Choi, Y. \& Veenhoven, R. (2009)

IQ and happiness

Working paper, Erasmus University Rotterdam

Diener, E., Lucas, R.E., Smith, H.L. \& Suh, E.M. (1999)

Subjective Well-Being: Three Decades of Progress

Psychological Bulletin, 125: 276-301

Frederickson, B.L. (1998)

What good are positive emotions?

Review of General Psychology, vol. 2, pp. 300-319

Harding, S. Fogarty, M. \& Phillips, D. (1986)

Contrasting Values in Western Europe

McMillan, London, UK

Hawkins, D.N. \& Booth, A. (2005)

Unhappily ever after: Effects of long-term, low-quality marriages on well-being

Social Forces, vol. 84, pp. 452-471

Headey, B. (2007)

The Set-Point Theory of Well-Being: Negative Results and Consequent Revisions

Social Indicators Research, 85: 389-403

HDCA Human Development and Capabilities Association

Capability and Functioning: Definitions and Justification

Assessed January 2009 at:

http://www.capabilityapproach.com/pubs/HDCA_Briefing_Concepts.pdf

Lane, R. E. (2000)

The Loss of Happiness in Market Democracies

Yale University Press, New Haven, USA 
Lynn, R. \& Vanhanen, T. (2002)

IQ and the wealth of nations

Preager, Westport CT, USA

Lyubomirsky, S., Diener, E. \& King, L.A. (2005)

The Benefits of Frequent Positive Affect: Does Happiness Lead to Success?

Psychological Bulletin, 131: 803 - 855

Nussbaum, M. C. \& Sen, A. eds. (1993)

The Quality of Life

Oxford: Clarendon Press

Nussbaum, M. C. (2000)

Women and Human Development: The Capabilities Approach

Cambridge University Press, Cambridge

Sen, A. (1985)

Commodities and Capabilities

Oxford: Oxford University Press

Veenhoven, R. (1984)

Conditions of happiness

Reidel (now Springer, Dordrecht, The Netherlands

Veenhoven, R. (1991)

Is happiness relative?

Social Indicators Research, 24: 1-34

Veenhoven, R. (1995)

Is happiness a Trait? Tests of the theory that a better society does not make people any happier

Social Indicators Research, 32: 101-160

Veenhoven, R. (2000a)

The four qualities of life: Ordering concepts and measures of the good life Journal of Happiness Studies, 1: 1 - 39

Veenhoven, R. (2000b)

Freedom and happiness: a comparative study in 44 nations in the early 1990's

Published in: Diener, E. \& Suh, E.M. (Eds.) 'Culture and subjective wellbeing', MIT press, Cambridge, MA USA, pp. 257-288

Veenhoven, R. (2005)

Gezond Geluk

Verkenningsstudie voor ZonMw in het kader programma 'Gezond Leven'

Veenhoven, R. (2005b)

Apparent quality of life: How long and happy people live

Social Indicators Research, 71: 61-86 
Veenhoven, R. (2006)

Quality of life in modern society, Measured with Happy Life Years

In: Yew-Kwang Ng \& Lok Sang Ho (Eds.) 'Happiness and Public Policy, Theory, Case studies and Implications' Palgrave-Macmillan, New York, pp.19-44

Veenhoven, R. (2007)

Does happiness matter? On the value of great happiness for a great number in: Joop Stam \& Ruut Veenhoven (Eds.): "Quality of life and happiness of people in Japan and The Netherlands", KIT Publishers, Amsterdam in cooperation with NIOD Encounters Series, Volume I, pp 156-163

Veenhoven, R. (2008)

Healthy happiness: Effects of happiness on physical health and the consequences for preventive health care

Journal of Happiness Studies, 9: 449 - 469

Veenhoven, R. (2009a)

How do we assess how happy we are?

In: Dutt, A. \& Radcliff, B. (eds.) Happiness, Economics and Politics, Edward Elger Publishers, USA

Veenhoven, R. (2009b)

World Database of Happiness. Collection of Correlational Findings

Erasmus University Rotterdam, The Netherlands

Assessed March 2009 at: http://worlddatabaseofhappiness.eur.nl

WDH-CF

World Database of Happiness, Correlational Findings

See Veenhoven 2009b 
Scheme 1

Four qualities of life

\begin{tabular}{|l|c|c|}
\hline & Outer qualities & Inner qualities \\
\hline Life-chances & Livability of environment & Life-ability of the person \\
\hline Life-results & Utility of life & Satisfaction \\
\hline
\end{tabular}


Scheme 2

Four kinds of satisfaction

\begin{tabular}{|l|c|c|}
\hline & Passing & Enduring \\
\hline Part of life & Pleasure & Part-satisfaction \\
\hline Life-as-a-whole & Peak-experience & Life-satisfaction \\
& & (happiness) \\
\hline
\end{tabular}


Scheme 3

Individual capability and happiness

\begin{tabular}{|c|c|c|c|}
\hline \multirow[t]{2}{*}{ Kind of capability } & \multirow{2}{*}{$\begin{array}{l}\text { Correlation with } \\
\text { happiness }\end{array}$} & \multicolumn{2}{|c|}{ Indications of causality } \\
\hline & & $\begin{array}{c}\text { Capability } \\
\downarrow \\
\text { Happiness }\end{array}$ & $\begin{array}{c}\text { Capability } \\
\uparrow \\
\text { Happiness }\end{array}$ \\
\hline \multicolumn{4}{|l|}{ General capability } \\
\hline \multicolumn{4}{|l|}{ Physical health } \\
\hline - negative (ill) & - & + & ++ \\
\hline - positive (fit) & + & & + \\
\hline \multicolumn{4}{|l|}{ Mental health } \\
\hline - negative (disturbed) & -- & + & + \\
\hline - positive (flourishing) & ++ & & + \\
\hline \multicolumn{4}{|l|}{ Specific capabilities } \\
\hline Intellectual (IQ) & 0 & & \pm \\
\hline Social & ++ & + & + \\
\hline Leisure & + & & \\
\hline Moral & + & + & + \\
\hline
\end{tabular}

$--=$ strong negative, $-=$ negative, $0=$ no correlation or effect, $+=$ positive,$++=$ strong positive Source: World Database of Happiness, collection of Correlational Findings (Veenhoven 2009b), 


\section{NOTES}

${ }^{1}$ Economists use the term 'utility' in a quite different meaning, that is, as the subjective satisfaction derived from consumption. That notion should be placed in the satisfaction quadrant at the bottom-right in scheme 1.

${ }^{2}$ A third kind of freedom mentioned by Bay is 'potential freedom', that is, being aware of chances and constraints. This kind of freedom is both environmental (availability of information) and individual (personal knowledge)

${ }^{3}$ In that chapter I have also distinguished two 'components' of happiness: an affective component (Hedonic level of affect) and a cognitive component (Contentment), which are seen to function as subtotals in the overall evaluation of life. That conceptualization is elaborated in Veenhoven 2009a.

${ }^{4}$ I have discussed the various qualms about the value of happiness elsewhere (Veenhoven 2007).

5 The term 'flourishing' is sometimes used as a synonym for 'quality-of-life' or 'wellbeing', and is then a generic for all the qualities mentioned in scheme 1 . The term is also used as a synonym for 'eudemonia' and then denotes the right column of 'inner qualities' in scheme 1 . In each case happiness is indicative for these wider qualities, yet not the same. If people live happy, their environment is apparently sufficiently livable and their abilities apparently appropriate. This notion of apparent quality-of-life is discussed in more detail in Veenhoven $2005 b$.

${ }^{6}$ There is much more detail in the research literature than I can report in this paper, e.g. multivariate analyses and comparisons across different publics. What counts here is the general picture. The interested reader can find detail in the indicated sections of the World Database of Happiness, which is free available at the internet.

${ }^{7}$ WDH-CF, 'Physical health' (code P6) and 'Mental health' (code M7)

${ }^{8}$ WDH-CF, 'Physical handicap' (code H2.2.1.2), 'Change in physical health (P6.1.2) and 'Chronic illness (P6.4.2.2)

${ }^{9}$ WDH-CF, 'Intelligence' (code I3). See also: Choi \& Veenhoven (2006)

${ }^{10}$ WDH-CF, 'Earlier cleverness' (code P1.2.14)

${ }^{11}$ WDH-CF, 'Level of school education' (code E1.2.1)

${ }^{12}$ WDH-CF, 'Earlier educational level' (code E1.1.1)

${ }^{13}$ WDH-CF, 'Ability to maintain intimate contacts' (code I6.4.1)

${ }^{14}$ WDH-CF, 'Assertive' (code P4.8)

${ }^{15}$ WDH-CF, 'Empathic' (code P4.33)

${ }^{16}$ WDH-CF, 'Extravert' (code P4.39)

${ }^{17}$ WDH-CF, 'Kind' (code P4.64)

${ }^{18}$ WDH-CF, ‘Open’ (code P.76)

${ }^{19}$ WDH-CF, 'Sociable' (code P4.106)

${ }^{20}$ WDH-CF, 'Contacts with relatives' (code F3.2.2)

${ }^{21}$ WDH-CF, 'Number of friends' (code F6.2) and 'Contacts with Friends (code F6.3)

${ }^{22}$ WDH-CF, 'Popularity' (code P9.2) 
${ }^{23}$ WDH-CF, 'Social participation' (codes S6, S7, S8)

${ }^{24}$ WDH-CF, 'Social support' (codes S10, S11)

${ }^{25}$ WDH-CF, 'Current leisure activity' (code L3.3)

${ }^{26}$ WDH-CF, 'Satisfaction with leisure' (code L3.4.3)

${ }^{27}$ WDH-CF, 'Earlier leisure ' (code L3.1.1)

${ }^{28}$ WDH-CF, 'Skill in sports' (code S12.2.3)

${ }^{29}$ WDH-CF, 'Social values' (code V2.2.2)

${ }^{30} \mathrm{WDH}-\mathrm{CF}$, 'Earlier values' (code V1.1.1)

${ }^{31}$ WDH-CF, 'Solidarity' (code P4.107)

${ }^{32}$ WDH-CF, 'Trust in people' (code P4.115)

${ }^{33}$ WDH-CF, 'Trust worthy' (code P4.116)

${ }^{34}$ WDH-CF, 'Moral' (code P4.70)

${ }^{35}$ WDH-CF, 'Average health of citizens' (code N7.2.1)

${ }^{36}$ WDH-CF, 'Literacy and schooling' (code N4.7.1)

${ }^{37}$ WDH-CF, ‘Modal extraversion' (code N3.39)

${ }^{38}$ WDH-CF, 'Modal trust' (code N3.115)

${ }^{39}$ WDH-CF, 'Modal honesty' (code N3.50)

${ }^{40}$ WDH-CF, 'Condition of the nation: Corruption' (code N4.9.1)

${ }^{41}$ This drive to use one's potentials is also known by the names of 'mastery needs' and 'exercise needs'. Though often seen as something 'high', these needs exist in also in little children, as manifested in play, and in 'lower' animals.

${ }^{42}$ WDH-CF, 'Later school success' (code S1.1.4.3)

${ }^{43}$ WDH-CF, 'Later educational level' (code E1.1.4)

${ }^{44}$ WDH-CF, 'Later cleverness' (code P5.2.14)

${ }^{45}$ WDH-CF, 'Later kindness' (code P5.2.64)

${ }^{46}$ WDH-CF, 'Later trust' (code P5.2.115)

${ }^{47}$ WDH-CF, 'Later values' (code V1.4.1) 